\title{
AS IMPLICAÇÕES E O RESPALDO DA OBRA DE ROUSSEAU NA EDUCAÇÃO
}

\author{
Míriam Benites Rios \\ Lilian Soares Alves Branco \\ Elaine Conte
}

\section{Resumo}

Esse artigo resulta de um exercício hermenêutico inspirado na obra Emílio ou da Educação, de Jean-Jacques Rousseau (1762), reconhecidamente um expoente da pedagogia moderna. Propomos aqui uma reflexão sobre a perspectiva pedagógica visionária de Rousseau voltada à valorização da liberdade da criança no mundo sociocultural, tendo em vista os saberes e potencialidades do pensamento pedagógico à formação criativa mais ampla. Para isso, elegemos como dispositivo de análise as principais ideias defendidas por Rousseau, para examinar as implicações em diferentes abordagens de educação baseadas em práticas que potencializam as dimensões humanas, no sentido de compreender as complexidades da educação e da infância no presente.

Palavras-chave: educação; Rousseau; pedagogia moderna; faculdades humanas.

\section{THE IMPLICATIONS AND RESPONSE OF ROUSSEAU'S WORK IN} EDUCATION

\begin{abstract}
This article is the result of a hermeneutic exercise inspired by Jean-Jacques Rousseau's (1762) work Emile or Education, recognized as an exponent of modern pedagogy. We propose here a reflection on Rousseau's visionary pedagogical perspective aimed at valuing the freedom of children in the educational world, in view of the knowledge and potentialities of education. For this, we have chosen as a device of analysis the main ideas defended by Rousseau, to examine the implications in different approaches of education based on practices that potentiate the natural human faculties, in order to understand the present narrative complexities.
\end{abstract}

Keywords: education; Rousseau; modern pedagogy; human faculties.

\section{LAS IMPLICACIONES Y EL RESPALDO DE LA OBRA DE ROUSSEAU EN LA EDUCACIÓN}

\section{Resumen}

Este artículo resulta de un ejercicio hermenéutico inspirado en la obra Emilio o de la Educación, de JeanJacques Rousseau (1762), reconocidamente un exponente de la pedagogía moderna. Proponemos aquí una reflexión sobre la perspectiva pedagógica visionaria de Rousseau orientada a la valorización de la libertad del niño en el mundo sociocultural, teniendo en cuenta los saberes y potencialidades a la educación. Para ello, elegimos como dispositivo de análisis las principales ideas defendidas por Rousseau, para examinar las implicaciones en diferentes enfoques de educación basadas en prácticas que potencian las facultades humanas naturales, en el sentido de comprender las complejidades narrativas presentes.

Palabras clave: educación; Rousseau; pedagogía moderna; las facultades humanas. 
INTRODUÇÃO

Não se conhece a infância: com as falsas ideias que dela temos, quanto mais longe vamos mais nos extraviamos. (ROUSSEAU, 1995, p. 8).

Ao resgatarmos algumas ideias inspiradoras do filósofo modernista Jean-Jacques Rousseau (1712-1778), consideramos a visão pedagógica de que a natureza humana não produz nada de supérfluo quando desvela o olhar metafórico1, originário da infância. Rousseau é considerado um dos principais teóricos da pedagogia moderna, por ter sido um dos primeiros a se preocupar com a formação antropológica e a educação das crianças, valorizando seus interesses e expressões, para estudar e aprender com as faculdades da infância, cuja inspiração vem da natureza e necessita de uma atitude de abertura pedagógica para escutar a criança, para conhecer e ensinar coisas úteis e fundamentais ao diálogo humano. Rousseau não justifica a ideia de que o ensino deva obedecer a um conjunto de técnicas, rompendo assim com os modelos tradicionais da época e proclamando que a criança não tem que se tornar outra coisa senão aquilo que ela deseja ser, respeitando-se assim o ritmo de crescimento e valorizando as características da infância (SOËTARD, 2010). De acordo com a proposta idealizada por Rousseau, o educando passa a ser o centro do processo de ensino e de aprendizagem, exercendo uma posição ativa em relação ao conhecimento e à complexidade de práticas que potencializam a liberdade e a multiplicidade de vozes, dando conta da natureza humana.

Nessa perspectiva, Rousseau enfatiza que o processo educacional precisa iniciar ainda na infância, com vistas a preservar a bondade, a inocência e as virtudes da natureza humana, como condição para garantir que o desenvolvimento físico e cognitivo da criança seja respeitado na estrutura fundamental da comunicação. Para tanto, trazemos para o diálogo as perspectivas de Vygotsky (1896-1934), Piaget (1896-1980), Antunes (1998), Gardner (1995), dentre outros, a ponto de nos indagarmos sobre a experiência e as preocupações de Rousseau com a educação e a infância. Com tal foco, questionamos a viabilidade e a importância da manutenção dessa concepção no contexto atual, de modo a garantir não só a formação cognitiva do educando, mas visando preparálo para o exercício da cidadania crítica em tempos de reconfiguração das relações entre educador e educando, dos sentidos de ensinar e aprender, da (re)construção de conhecimentos, na tentativa de educar para a emancipação. Nesse intuito, buscamos também discutir os propósitos de Rousseau face ao tempo atual ou fazendo analogias com a realidade contemporânea, retomando algumas pesquisas recentes (TREVISAN, ROSA, 2018; DALBOSCO, 2018; PAIVA, 2019; KLEIN, 2019). Trata-se de incluir ou dialogar com esses textos mais atuais para darmos conta das novas configurações pedagógicas propostas por estes estudiosos, frente a um contexto educacional com desafios complexos incluindo as diferenças (GÓMEZ, 1998). Daí a necessidade de se adotar práticas educativas que conferem uma posição ativa aos estudantes na produção de conhecimentos contemporâneos, para reconhecer as singularidades e as múltiplas capacidades do ser humano. "[...] Rousseau questionou justamente esse distanciamento, a antítese fundamental criada entre a natureza do homem e o desenvolvimento da civilização", refletindo na mera reprodução da tradição cultural em formas de ensino descontextualizadas da cultura da infância (TREVISAN, ROSA, 2018, p. 820). Considerando as transformações no contexto contemporâneo, questiona-se se estas ideias ainda são pertinentes para restabelecer uma formação global que ouve a vOz da

\footnotetext{
${ }^{1}$ Qualquer conceito no início era uma metáfora, assim como o olhar humano é sempre metafórico porque está em relação com o mundo e com os objetos do mundo, atribuindo sempre novos sentidos.
} 
consciência, observa e valoriza a diversidade das formas da natureza humana desde a infância, em tempos de reconfiguração das relações, de sentidos e de conhecimentos na vida em sociedade.

\section{AS OBRAS DE ROUSSEAU E OS ENTRELAÇAMENTOS CONTEXTUAIS}

Antes de abordar as concepções de Rousseau sobre a educação e o desenvolvimento infantil, torna-se necessário dizer que "Rousseau experimentou as duas grandes vertentes do cristianismo cujos conflitos e tensões marcam toda a história moderna: o Protestantismo e Catolicismo romano" (STRECK, 2004, p. 19). Tudo indica que a obra filosófica sobre a natureza do homem de 1762 - Emílio ou da Educação deu respaldo à pedagogia moderna como arte de ensinar. No romance, em que foca no que as crianças estão em condições de aprender para potencializar o desenvolvimento delas, cria em sua teoria, o estudante Emílio, um educando imaginário, órfão e rico, delineando na obra, enquanto preceptor de Emílio, a trajetória educativa necessária desde seu nascimento até seu casamento. Emílio representa uma força enunciativa de uma educação voltada para natureza humana emancipatória em oposição a um modelo de educação formalista, técnico, impositivo, homogeneizador e racional.

Defensor de uma educação libertadora, fundamentada em uma pedagogia natural, Rousseau entende que Emílio deve ser criado no respeito e direito à liberdade, de modo que possa brincar e interagir com e pela natureza, pois entende que só assim a função da educação cumprirá seu papel, que é o de ensinar a criança a viver, a aprender a pensar e a exercer a liberdade, pois entende que somente assim poderá “[...] conquistar a própria liberdade e autonomia pessoal além do encontro conflituoso com a dura realidade do mundo, com a realidade do outro, com a da sociedade" (SOËTARD, 2010, p. 17). Nesse sentido, Rousseau destaca a importância da figura do que chama de preceptor ou pedagogo, o qual deverá acompanhar e coordenar a criança nessa jornada formativa, sendo este fundamental para a conquista da liberdade e autonomia, mas de um modo que sua vontade não interfira ou se sobreponha a vontade da criança. Para delinear como deve ser o processo de criação e de educação de Emílio, Rousseau divide a obra em cinco extensos livros ou capítulos, enfatizando em cada um deles o período da infância, desde os primeiros cuidados com o nascimento até a idade adulta, quando, enfim, Emílio estará em condições de aprender de forma livre e autônoma, apto para se engajar na vida em sociedade.

Antes de investigar cada um dos cinco capítulos de Emílio, torna-se importante ressaltar que Rousseau estava ciente de suas limitações de conhecimento, em termos do pensar com fontes científicas, quando se propõe a retratar fielmente o ideal de desenvolvimento e a educação de uma criança, o que faz de Emílio um romance pedagógico. A inspiração para o livro brota de um pensador solitário que visa melhor conhecer a criança e a infância, objetivando a formação do homem para a vida, e não em formatar um manual ou um guia de técnicas aplicáveis na totalidade ou exauridas de contradições e armadilhas.

Leitores, lembrai-vos sempre de que quem vos fala não é um sábio nem um filósofo e sim um homem simples, amigo da verdade, sem partido, sem sistema; um solitário que, vivendo pouco com os homens, tem menos oportunidades de se imbuir de seus preconceitos e mais tempo para refletir sobre o que o impressiona quando com eles vive. Meus raciocínios são menos baseados em princípios do que em fatos; e creio não poder colocar-vos ao alcance de julgá-los e senão vos relatando algum exemplo das observações que me sugerem. (ROUSSEAU, 1995, p. 79). 
No Primeiro Livro - Primeira educação ou idade da naturez̧a: infância de zero a dois anos - é a fase da primeira educação, a mais importante de todas para Rousseau, pois nela são lançadas as bases para constituição do ser humano. Essa primeira educação cabe às mulheres, pois o vínculo com a mãe pelo aleitamento materno é fundamental. No entanto, Rousseau destaca que o pai também deve assumir responsabilidades na tarefa de educar os filhos, indo além do gerar e sustentar os mesmos. A educação deve ser um processo espontâneo, de livre movimentação física da criança, para aquisição do conhecimento pelos sentidos. Neste caso, a educação da criança, desde seu nascimento até a vida adulta, deve ficar sob os cuidados de um preceptor, um profissional jovem e que seja "[...] capaz de se colocar com a criança em suas brincadeiras e maneira de ser" (STRECK, 2004, p. 41). Numa concepção de que "[...] nascemos fracos, precisamos de força; nascemos desprovidos de tudo, temos necessidade de assistência; nascemos estúpidos, precisamos de juízo. Tudo o que não temos ao nascer, e de que precisamos adultos, é-nos dado pela educação" (ROUSSEAU, 1995, p. 12).

O pensador sinaliza a existência de três tipos de educação ou mestres, a saber: a educação da natureza (desenvolvimento interno do homem), a educação dos homens (faz uso desse desenvolvimento eternamente, com o objetivo de fazer de cada homem um cidadão) e a educação das coisas (sobre o que se ganha através das nossas experiências). Nesse cenário, o grande equívoco é que estas três formas de educação não eram tratadas de forma diferenciadas, mas postas em coalisões, confrontadas e colocadas em oposição. O propósito de Rousseau era a junção dessas três formas de educar com intuito de eliminar essa oposição e ressignificar essa articulação num ideal de educação. Basicamente, neste primeiro livro, o objetivo da educação de Emílio nessa etapa é de ajudar a criança na sua carência, fornecer-lhe somente o que é útil, sem fantasias, entender sua linguagem e lhe dar o que ordena sua natureza, criar condições para sua independência, para que tenha discernimento das coisas.

Esta parece ser uma questão que emerge nas últimas décadas em torno de como desenvolver e ressignificar ações pedagógicas na Educação Infantil, pondo em suspeição o trabalho diretivo do professor e o seu conhecimento dirigido por técnicas de ensino, que causam um desconforto e uma inadequação com a cultura da infância. A dimensão global e integral da criança implica no desenvolvimento dos sentidos capazes de satisfação do ser humano que vem da sensibilidade e se confirmam como faculdades humanas que precisam ser cultivadas ou criadas. A própria história da humanidade revela que a apropriação da realidade humana acontece por meio de relações entre seres ativos, produtivos e sensíveis com o mundo nas formas de ver, ouvir, cheirar, sentir, desejar, amar, enfim, funções autênticas da própria (inter)subjetividade. Sem sombra de dúvidas, a criança se apropria do mundo objetivo com a finalidade de reconhecer sua essência interior na luta por reconhecimento e contra sua repressão. A criança forma seus sentidos, sua sensibilidade e relações sociais num processo dialético e interativo com a própria natureza e na comunicação com o outro, assimilados no processo cultural concreto e livre da infância. Isso porque um trabalho verdadeiramente livre e educativo com as crianças, por exemplo, exige um esforço mais intenso quando está voltado a uma formação cultural à autonomia, pois implica o devir formativo do ser em obra.

No Segundo Livro de Emílio - Dois aos 12 anos: uma educação pela natureza e uma razão sensitiva -, Rousseau compreende que nessa fase da infância é mais importante a prática de bons atos do que a aquisição de grandes conhecimentos, seja através de livros ou de lições. A prioridade nessa experiência da infância é reconhecer o mundo externo, aprender a ler é secundário. Por isso a importância de explorar a imaginação, os experimentos, as fantasias, as sensações, tendo somente o que é necessário através da natureza, já que a primeira razão do homem é uma racionalidade 
perceptiva e emocional, que será a base à razão intelectual. Nesse sentido, Rousseau (1995, p. 94) afirma que:

[...] como tudo que entra no conhecimento humano entra pelos sentidos, a primeira razão do homem é uma razão perceptiva; ela é que serve de base à razão intelectual: nossos primeiros mestres de filosofia são nossos pés, nossas mãos, nossos olhos. Substituir tudo isso por livros, não é ensinar-nos a raciocinar, é ensinar-nos a nos servirmos da razão de outrem; é ensinar-nos a acreditarmos muito e a nunca sabermos coisa alguma.

Nessa lógica, considera nesta fase uma educação que estimule e dê possibilidade à criança formar ideias a partir das próprias experiências. Não há por que se apressar em apresentar leituras e conteúdos prontos ou ensinamentos sobre virtudes e verdades unívocas. Trata-se de priorizar uma educação negativa, com demandas contraditórias e interesses diferentes, pois o segredo da boa educação para Rousseau não é ganhar tempo, mas sim perdê-lo, zelando pelo desenvolvimento do corpo, dos órgãos, dos sentidos, da força, deixando a alma ociosa o quanto for possível. Se a liberdade individual passa pelo mundo social e pela superação dos medos, então, “[...] cada idade, cada condição na vida tem sua perfeição conveniente, sua espécie de maturidade própria. Amiúde ouvimos falar de um homem feito; mas consideremos uma criança feita" (ROUSSEAU, 1995, p. 125). De acordo com Rousseau é neste período que realmente se inicia a vida e que a criança toma consciência de si mesma. Partindo do princípio de que a criança é um ser pensante e atuante, a lição de moral deve ser a de fazer o bem, a correção não deve ser verbal, mas precisa ser construída na prática e aplicada pela experiência formadora, educando-as pelo exemplo, de modo que gravem na memória e no coração.

O Terceiro Livro de Emílio - Dos 12 anos aos 15 anos: educação útil e profissão -, Rousseau destaca que nesta fase é a ocasião de se preparar para o mundo do trabalho, dadas as suas limitações, tendo como critério a utilidade pragmática, o que não se confunde com uma educação utilitarista. Trata-se de projetar uma educação que ajude o jovem a encontrar seu lugar no mundo, num mundo incerto, em que já não está predeterminado desde o nascimento, mas em processo de formação e (re)construção do conhecimento. Para Rousseau, esta seria a terceira fase da infância, antes da adolescência e nesse período seriam incorporados dois aspectos novos: a aprendizagem das ciências e a escolha da profissão. Sobre o ensino das ciências, Rousseau destaca que de nada adianta incorporar ideias e conhecimentos que não sejam úteis nesse momento, porque a aprendizagem se dará quando a criança estiver atenta ao que acontece na natureza ou quando for despertada sua curiosidade. Então, o desafio do preceptor nesta etapa é estimular e colocar questões que ajudem a encontrar respostas e estabelecer relações entre os fenômenos estudados. Nesse sentido, para aprender a ciência devemos (re)inventá-la, buscando novas reflexões, desacomodações e transformações do conhecimento.

Durante a primeira infância o tempo era longo: só procurávamos perdê-lo, de medo de mal o empregar. Agora é o contrário e não temos mais bastante para fazer tudo que seria útil. [...] Não se trata de ensinar-lhe as ciências e sim dar-lhe inclinação para as amar e métodos para as aprender, quando a inclinação se tiver desenvolvido bastante. Eis certamente um princípio fundamental de uma boa educação. (ROUSSEAU, 1995, p. 181).

Tudo indica que um bom ensino não depende do uso de artefatos sofisticados ou de truques psicológicos assertivos, mas de descobertas, emoções, motivações e sentimentos, em que erro faça parte do aprendizado. Além disso, defendia que os enganos retroalimentam os processos de 
aprendizagem, levando as crianças e jovens a fazer as devidas relações e buscar o verdadeiro sentido do seu processo de conhecimento.

Sem dúvida aprendemos noções bem mais claras e bem mais seguras das coisas que aprendemos assim por nós mesmos, que das que recebemos dos ensinamentos de outrem; e, além de não acostumarmos nossa razão a submeterse servilmente à autoridade, tornamo-nos mais engenhosos em encontrar relações, em ligar ideias, em inventar instrumentos do que quando, adotando tudo isso tal qual nos é dado, deixamos cair nosso espírito de preguiça. (ROUSSEAU, 1995, p. 188).

Desse modo, Rousseau critica a educação através dos livros da época, pois estes ensinam a falar coisas que os estudantes não sabem, apenas como mera repetição. A autocrítica era feita à educação livresca que produzia fadiga cultural e não homens úteis para uma sociedade emergente, o que atrofiava a capacidade de fazer perguntas e buscar respostas. As ilusões fundamentalistas desse modelo giravam em torno de uma educação das coisas estabelecidas entre o homem e o objeto, sem uma preocupação com as palavras, com o respeito aos tempos e ritmos de estudo ou ao que era útil ao conhecimento da criança.

Tratai de ensinar a criança tudo o que é útil à sua idade e vereis que todo seu tempo estará mais que cheio. Por que quereis, em detrimento dos estudos que lhe convém hoje, aplicá-la nos de uma idade a que não é certo que chegue? [...] O que sei é que é impossível aprendê-lo antes; porque nossos verdadeiros mestres são a experiência e o sentimento e nunca o homem sente bem o que convém ao homem senão nas situações em que se encontra. (ROUSSEAU, 1995, p. 190-191).

Rousseau nos leva a refletir sobre a utilização dos materiais didáticos no processo de ensino e de aprendizagem, do cuidado na escolha desses recursos e do objetivo desse uso, pois estes devem ser apropriados à fase de desenvolvimento em que a criança se encontra, como um meio para estimular o conhecimento, não como um fim em si. Ainda destaca nessa fase a importância da escolha da profissão, pois do mesmo modo que Emílio criava os instrumentos para pesquisa, ele deveria criar os instrumentos para seu trabalho e assim escolher uma profissão que favorecesse a sua independência. Sem depender de escravos e patrões cuja lei da necessidade recai na miséria humana, defendia a realização de um trabalho com sabedoria e condizente com a condição humana. Desse modo, Rousseau destaca a escolha de Emílio para marcenaria (artesão), frisando a valorização do trabalho manual de artífice, que foi menosprezado pela nobreza no momento em que a estética se juntou à utilidade, modificando o entendimento de algumas profissões. Importa, porém, que seja um trabalho "[...] limpo, útil, que pode ser feito em casa, cansa suficientemente o corpo, exige do trabalhador habilidade e inteligência, a elegância e o gosto não estão excluídos da forma das obras que a utilidade determina" (ROUSSEAU, 1995, p. 258). Rousseau acreditava que trabalhar era um dever do homem social, buscando neste trabalho uma espécie de apreciação por ter sido bem feito, no sentido de trabalhar como um camponês e pensar como um filósofo, superando a ignorância.

Essas questões constituem o pano de fundo das experiências educativas em diálogo com a alteridade para a produção de conhecimento em todas as instâncias da vida moderna, bem como desencadeiam formas singulares de criação e de intervenção crítica na realidade. Nas palavras de Dalbosco (2019, p. 1):

O diálogo vivo e criativo com a tradição pedagógica é um recurso poderoso para a construção de ferramentas conceituais apropriadas que dão solidez teórica ao 
campo pedagógico, capacitando-o para compreender a atualidade educacional. No âmbito da tradição pedagógica clássica, o vínculo entre condição humana e teoria educacional constitui-se no fio condutor indispensável para se investigar o processo formativo educacional humano e elaborar propostas pedagógicas à realidade educacional.

No Quarto Livro - Dos 15 a 25 anos: consciência e sentimentos do homem -, Rousseau destaca que é nesse período da vida o momento de conquistar a sociedade. É um novo cidadão que se apresenta à sociedade, um indivíduo com autonomia e capacidade de enfrentar os desafios do mundo. Tal engajamento social passa pela capacidade de pensar e coordenar ações por correlação, entre as exigências formativas e o próprio contexto, representando, segundo Rousseau, como se os indivíduos tivessem dois nascimentos, o primeiro biológico para a vida e o segundo de sentido espiritual e para a existência coletiva. Essa fase representa o florescimento da pessoa para a vida moral, social e religiosa, com tomada de consciência de sua própria vida para a sobrevivência em sociedade, agora com posições, conceitos, (contra)argumentos e ponderações. Rousseau (1995, p. 41) destaca que "Emílio não é um selvagem a ser relegado aos desertos, é um selvagem para morar nas cidades". Cabe refletir sobre o sentimento e o que se deseja do mundo, é o momento de olhar para si e se posicionar frente aos conhecimentos produzidos pela sociedade, buscando o fortalecimento dos projetos sociais.

Nesse livro as paixões e sentimentos são afloradas nas relações com o outro, saindo de si e se identificando com o ser que sofre, seja animal ou pessoa, e assim é introduzido o estudo sobre a vida das pessoas não como memorização, mas como um ponto de partida para a história. Então, com o intuito de aprender a ler o coração dos homens seria possível desenvolver a capacidade de julgar os fatos por si mesmo, a partir da experiência vivida. Segundo Rousseau (2005, p. 290), “[...] o que torna mais afirmativo [...] é que em lugar de me entregar ao espírito de sistema, dou o menos possível ao raciocínio e só confio na observação. Não me baseio no que imaginei e sim no que vi”.

Nessa leitura fenomenológico-hermenêutica Rousseau destaca que somente nessa fase se teria condições de compreender que os mistérios da religião são incompreensíveis e que a inteligência divina é puramente intuitiva, já que tudo abarca e confere movimento ao mundo, além de formar todo o sistema da natureza viva, mesmo que não seja visível e palpável, dá sentido à vida humana. A formação desse indivíduo é construída a partir da multiplicidade de pequenas experiências, destacando a profundidade não a quantidade dessas experiências. Rousseau destaca que a educação do cidadão se torna impossível sem a educação do homem, dotado de sua verdadeira liberdade, consciência e racionalidade.

No último e Quinto Livro - A educação da Mulher: Sofia e o ser social —, Rousseau destaca que existem diferenças na educação do homem e da mulher. É importante analisar o pensamento e o contexto em que a obra foi escrita, numa sociedade em que se percebia a mulher como submissa e servidora do homem, filhos e família, totalmente dependente do homem e com a função de agradar e atender as necessidades do homem. Na perspectiva de Rousseau, a igualdade de sexos é perigosa quando subsumida à tendência manipuladora das correntes institucionais, acreditando que a mulher consegue se libertar da realidade em que vive, através de um poder que a natureza lhe dá. "[...] esse domínio é das mulheres e não pode ser-lhes tirado, mesmo quando abusam dele; se o pudessem perder, de há muito o teriam perdido" (ROUSSEAU, 1995, p. 308). Em outras palavras, ao buscar a igualdade de gênero as mulheres acabavam por tornarem-se mais submissas aos homens.

Porém, é nesta relação de Emílio com Sofia, que a mulher aprende o que deve ver e é com a mulher que o homem aprende o que deve fazer. Nesse contexto, a mulher desde o início surge como um ser social, sem ela, toda a cuidadosa educação de Emílio corre o risco de cair por terra. 
$\mathrm{Na}$ visão de Rousseau, é através da inter-relação e intervenção da mulher (mãe e esposa) na existência mundana que o indivíduo se constitui como sujeito social.

Assim, toda a educação das mulheres deve ser relativa ao homem. Serem úteis, serem agradáveis a eles e honradas, educá-los jovens, cuidar deles grandes, aconselhá-los, consolá-los, tornar-lhes a vida mais agradável e doce; eis os deveres das mulheres em todos os tempos e o que lhes devemos ensinar já na sua infância. Enquanto não remontarmos a esse princípio, afastar-nos-emos do objetivo e todos os preceptores que lhes derem servirão de nada nem para sua felicidade nem para a nossa. (ROUSSEAU, 1995, p. 312).

No movimento dialético dessa relação é que se constrói uma nova sociedade, pois a mulher aprendeu a controlar seus sentimentos para garantir a ordem civil. Para Rousseau é a mulher que faz um bom filho, é ela quem o satisfaz e governa o bom marido, também garante as condições para um bom pai. A ideia do casamento é garantir a felicidade do homem, no seu estado de gozo e paz, para que se possa cumprir com os deveres sociais. Sobre a relação da mulher com a ciência, Rousseau (1995) aborda que o conhecimento das mulheres é um conhecimento prático, dotado de significado e utilidade, assim como a educação dos homens, fazendo aplicação do que os homens descobrem. Desse modo, compete:

[às] mulheres encontrarem, por assim dizer, a moral experimental, a nós o cuidado de sistematizá-la. A mulher tem mais espírito, o homem mais gênio; a mulher observa, o homem raciocina: dessa cooperação resultam a luz mais clara e a ciência mais completa que o espírito humano pode tirar de si mesmo, o conhecimento mais seguro, em suma, de si e dos outros que se acham ao alcance de nossa espécie. E eis como a arte pode tender incessantemente a aperfeiçoar o instrumento dado pela natureza. (ROUSSEAU, 1995, p. 335).

Cabe ressaltar que a educação das mulheres, os ensinamentos e aprendizagens sociais estavam relacionadas ao homem, no sentido de se complementarem e constituir-se como um ser social. E ao ler esse clássico, é possível perceber as valiosas contribuições que Rousseau trouxe à educação, e mesmo sendo elaborado em outra época, apresenta-se como inspiração para continuarmos enfrentando e refletindo alguns dos mesmos desafios por ele proposto. Desse modo, buscamos na próxima seção analisar as clássicas contribuições de Rousseau com outros teóricos contemporâneos.

\section{A PEDAGOGIA MODERNA DE ROUSSEAU REVISITADA COM OUTRAS PERSPECTIVAS}

A proposta de uma educação natural em Rousseau não é baseada nas formas da sociedade ou na escola tradicional de sua época, mas sim no conhecimento da verdadeira natureza do homem. Portanto, mediante uma investigação e conhecimento rigoroso sobre a natureza da criança seria possível cultivar o exercício de liberdade para dar conta das necessidades humanas. Esse enfoque confere originalidade ao seu pensamento e altera o conceito de ensino da modernidade, pois ao valorizar a criança em todas as suas dimensões, físicas, psíquicas, afetivas, emocionais, intelectuais, sociais, culturais e econômicas lança a semente para a revisão do conhecimento sobre a educação infantil. A defesa de uma educação pedocêntrica (centrada na criança) é justificada numa interação com a natureza, no sentido de valorizar e reconhecer os instintos naturais e as descobertas pelo simples ato de brincar, correr, saltar e jogar que as crianças possuem. Os elementos ético-morais 
de Rousseau começam com o nascimento e se alinham ao valor conferido à infância, num aperfeiçoamento que vai além de um regime forçado de conhecimentos preestabelecidos.

Diante disso, percebe-se que as preocupações educacionais inseridas por Rousseau e outros teóricos modernistas, referentes ao desenvolvimento e processos de aprendizagem da criança, tiveram continuação e inspiraram teóricos como Piaget (2007), Vygotsky (1991) e Gardner (1995), dentre outros. O aprofundamento de tais investigações passou pela concepção de Piaget e seus estudos sobre os estágios de desenvolvimento infantil com vistas a entender a gênese do conhecimento. Vygotsky com sua teoria sociointeracionista direciona tais questões para as formas como o sujeito interage e elabora seus conhecimentos a partir de aproximações e de relações sociais. Assim como a necessidade de reconhecimento e da valorização das inteligências múltiplas de Gardner, e que são reforçadas por Celso Antunes (1998) na ideia de que as experiências que levam à aprendizagem, sendo necessários estímulos na idade certa, para que essas inteligências sejam aperfeiçoadas. Com base nesses desdobramentos, neste tópico realizamos, por meio de um exercício hermenêutico, a articulação dessas inquietações em Rousseau, considerando a aprendizagem nos primeiros anos de vida e a infância até os 12 anos. De acordo com Hermann (2003), pela sua possibilidade compreensiva, a abordagem hermenêutica permite que a educação se torne esclarecida para si mesma e reconheça sua própria racionalidade. Por intermédio dessa abordagem, a educação pode interpretar o seu próprio modo de ser e agir na formação humana em sua pluralidade e contextos.

As concepções de desenvolvimento e de aprendizagem, na perspectiva de Piaget (2007), nascem da tentativa de entender a gênese do conhecimento, a partir da relação entre raciocínio lógico e resolução de problemas. Focado nessa problemática, Piaget (2007) procura fornecer uma resposta às inquietações sobre os processos cognitivos iniciais que, de acordo com ele, seriam questões mal resolvidas, oriundas do empirismo clássico. Para o autor, as grandes inquietações giram em torno da relação entre sujeito e objeto, em que supõe não ser o conhecimento exclusivamente oriundo do objeto. Nesse sentido, Piaget destaca que, ao contrário das posições clássicas, há que se considerar a existência de um sujeito conhecedor de seus potenciais em diferentes graus, objetos e instrumentos de interação entre os mesmos, numa relação de troca entre sujeito e objeto, e vice-versa. Essa relação, nas análises iniciais da psicogênese se contradiz, uma vez que o conhecimento "[...] resultaria de interações que se produzem a meio caminho entre sujeito e objeto, e que dependem, portanto dos dois ao mesmo tempo, mas em virtude de uma indiferenciação completa e não de trocas entre formas distintas" (PIAGET, 2007, p. 8). Isso significa que o conhecimento resulta dessa interação, destacando o papel da ação como fonte do desejo, em contraponto a percepção. $\mathrm{Na}$ teoria da descentração piagetiana, a fonte do conhecimento e da inteligência humana é a ação, especialmente no momento em que o sujeito assume, realiza e coordena perspectivas válidas para qualquer pessoa, por meio de atitudes de descentração compartilhada. Tal nível de descentração é iniciado aos 14 anos quando há uma evolução das capacidades da imaginação, do reconhecimento e da representação com o desenvolvimento no âmbito das emoções - fator importante para compreender os mecanismos da interação humana.

Contudo, Piaget (2007) faz uma divisão dos conhecimentos por níveis de desenvolvimento como foco de análise, reforçando que não há começos absolutos, mas passagens/aprimoramentos de conhecimentos nos diferentes níveis, que perpassam desde o nascimento até os 12 anos de idade. Tais níveis estão relacionados e correspondem às seguintes definições: sensório motor (zero a dois anos); primeiro nível do pensamento pré-operatório (2 a 4 anos); segundo nível préoperatório (5 a 6 anos); primeiro nível do estágio das operações concretas (7 e 8 anos); segundo nível do estágio das operações concretas (9 e 10 anos); estágio das operações formais (11 a 12 anos). 
Sinteticamente, o primeiro nível, sensório motor é composto pelas ações instrutivas que constituem o vínculo entre sujeito e objeto na fase inicial da vida, entre zero e dois anos. De acordo com Piaget (2007), o que marca essa relação é a indiferenciação entre sujeito e objeto, e centração das ações primitivas egocêntricas, potencializada pela falta de coordenação do agir, constituindo um mundo pequeno todo isolável da criança, exemplos disso seria chupar, olhar, agarrar. Entende-se que estas são as primeiras ações espontâneas da criança que envolve o sentir e o manipular, que são essenciais para o desenvolvimento cognitivo e a formação da inteligência emocional, necessitando ser estimuladas e aprimoradas. Ao tecermos analogias dessa fase destacada por Piaget (2007) com o pensamento de Rousseau, observamos que:

As primeiras faculdades que se formam e se aperfeiçoam em nós são as dos sentidos. São as primeiras que se deveriam cultivar e são as únicas que se esquecem ou as que mais se negligenciam. Exercer os sentidos não é somente fazer uso deles, é aprender a bem julgar por eles, é aprender, por assim dizer, a sentir; porque nós não sabemos nem apalpar, nem ver, nem ouvir senão da maneira que aprendemos. (ROUSSEAU, 1995, p. 101).

No pensamento pré-operatório, entre os 2 e os 4 anos, Piaget (2007) destaca que a criança atinge percepções mais gerais, globais, em que os esquemas mentais ainda não são transformados em conceitos e manipulados pelo pensamento, a não ser que seja manipulável concretamente, pois estabelecem pré-relações e pré-conceitos entre sujeito e objetos, o que significa atingir um meio termo entre esquema de ação e conceitos. Nesse caso, o sujeito da ação é pensado em suas características mais duradouras pela capacidade de seriação e expressão de imagens mentais ou linguagens. No segundo nível pré-operatório, entre 5 e 6 anos, a criança já é capaz de fazer o movimento de descentração de si, encaminhando pré-operações que se convertem em relações. Também, de acordo com Piaget (2007), nesta fase a criança já é capaz de classificar, avançando na dissociação dos elementos, sem ainda ser capaz de fazer a reversibilidade dos fatos, mas sendo capaz de fazer algumas relações.

Ações interiorizadas ou conceitualizadas revertidas em operações enquanto transformações reversíveis, numa combinação entre antecipações e retroações, marcam o primeiro nível do estágio das operações concretas (entre 7 e 8 anos). Para se chegar a este estágio, em seu aspecto lógico do processo de reversibilidade operatória, há que verificar a integração de três momentos: abstração reflexiva - estruturas inferiores para as superiores e classificações operatórias; coordenação ligação entre ordenações ou ligações parciais; autorregulação do processo coordenador equilibração das conexões dos dois sentidos, direito e inverso (PIAGET, 2007). Em suma, isso significa que nesse nível a criança é menos fantasiosa com relação ao que é real, mas as operações concretas ainda incidem sobre os objetos.

No segundo nível do estágio das operações concretas, entre 9 e 10 anos, já há uma equilibração geral das operações concretas, em que o sujeito apresenta domínio das operações infralógicas ou espaciais. Ou seja, capacidade de apresentar coordenação de pontos de vista em relação a um conjunto de objetos observados em diferentes ângulos e situações. Já no último estágio, o das operações formais incide a capacidade de realização de operações lógico-matemáticas de maneira depurada, por meio das estruturas formais que se constituem em torno dos 11-12 anos. Nesse sentido, a criança já é capaz de formar operações sobre hipóteses, que permitem o conhecimento ultrapassar o real, abrindo um caminho indefinido por meio de possibilidades entre diferentes combinações, libertando-se das construções graduais das operações. Perpassando pelos estudos de Piaget, com relação aos estágios de desenvolvimento do conhecimento na infância, verifica-se a relação direta com algumas das ideias contidas nos capítulos I e II de Emílio, em que 
Rousseau (1995) prega que de zero aos 12 anos, a educação precisa oferecer à criança caminhos para formar ideias a partir das próprias experiências, ou seja, através da interação e manipulação de diferentes objetos, zelando pelo desenvolvimento do corpo, da mente, dos sentidos, através de brincadeiras e jogos ao ar livre, que trabalhem a força e ao mesmo tempo estimulem a imaginação, os experimentos, as fantasias e as sensações investigadas.

A teoria sociointeracionista de Vygotsky (1991), respalda-se na concepção de um sujeito, biológico e social, que interage e elabora seus conhecimentos sobre os objetos, em um processo mediado pelo outro (símbolos). Nesse sentido, o conhecimento tem gênese nas relações sociais, sendo produzido na intersubjetividade e marcado por condições culturais, sociais e históricas. Conforme Rego (2008, p. 38), a abordagem sociointeracionista de Vygotsky tem por objetivo “[...] caracterizar os aspectos tipicamente humanos do comportamento e elaborar hipóteses de como essas características se formaram ao longo da história humana e de como se desenvolvem durante a vida de um indivíduo". Preocupado em compreender a evolução da cultura humana (sociogenético) e o processo de desenvolvimento individual (ontogenético), Vygotsky (1991) dedicou-se a investigar principalmente o desenvolvimento infantil, período em que surgem essas dimensões junto com a fala. Contrariando outros paradigmas, o desenvolvimento humano não é um processo previsível, universal, linear e gradual, pois está relacionado ao contexto históricocultural, em que o sujeito projeta-se "[...] de forma dinâmica (e dialética) através de rupturas e desequilíbrios provocadores de contínuas reorganizações por parte do indivíduo" (REGO, 2008, p. 58).

Com base nisso, Vygotsky (1984) considera que o desenvolvimento humano ocorre a partir das constantes interações com o meio social em que o sujeito está inserido, sendo a fala um importante elo das funções psicológicas humanas com as experimentações no mundo. Pensamento e linguagem, por meio da relação que ocorre num determinado grupo cultural, dão origem ao que o autor chama de funcionamento psicológico mais sofisticado, atividade tipicamente humana. Para Vygotsky (1984), através da aquisição da linguagem, a criança adquire formas mais complexas de se relacionar com o seu meio, de se comunicar com os indivíduos, fortalecendo os modos de agir e pensar. A relação entre desenvolvimento e aprendizagem representa o eixo central da pesquisa de Vygotsky (1984), momento em que identifica dois níveis de desenvolvimento: a conquista já efetivada e consolidada na criança - o nível de desenvolvimento real ou ativo; e o desenvolvimento potencial, capaz de ser construído ou realizado pela criança. Neste caso, a criança realiza tarefas ou soluciona problemas por meio do auxílio e colaboração de outra pessoa. A distância existente entre estes dois níveis Vygotsky (1984) denomina de zona de desenvolvimento potencial ou proximal (ZDP), para caracterizar as funções que ainda estão em processo de maturação. A linguagem é permeada por emoções e relações com o mundo, também é uma necessidade que se assemelha ao olhar, ao gesto, ao que chama a atenção e pode ser experimentado junto à realidade.

Linguagem é desejo, assim como a convivência é relação e conexão em que o olhar do outro valida ou não a ação, num processo em que constroem a consciência da sua própria prática. Outro ponto considerável nos estudos de Vygotsky é com relação à formação de conceitos enquanto um "[...] sistema de relações e generalização contido nas palavras e determinado por um processo histórico cultural” (REGO, 2008, p. 76). Na concepção de Vygotsky, desenvolvimento e aprendizagem estão inter-relacionados desde o nascimento da criança, dando origem aos conhecimentos construídos na experiência pessoal e concreta e no cotidiano da criança. Ao ingressar na escola, por exemplo, a criança passa a adquirir os conhecimentos sistematizados/organizados. Estes dois tipos de conhecimento estão intimamente relacionados, uma vez que no processo de constituição humana é possível destacar "[...] duas linhas qualitativamente diferentes de desenvolvimento, diferindo quanto à sua origem: biológica; de outro, 
as funções psicológicas superiores de origem sociocultural. A história do comportamento da criança nasce do entrelaçamento dessas duas linhas" (VYGOTSKY, 1984, p. 52). Assim como Rousseau, em se tratando da brincadeira, Vygotsky (1984) considera essa como uma importante ferramenta para estimular e provocar o desenvolvimento da criança. Nesse caso, refere-se ao brinquedo como a atividade em si, ao ato de brincar, em que estão inseridos tanto os jogos esportivos como brincadeiras que permitem o jogo e a troca de papéis sociais, como o faz-deconta, o brincar de médico, de supermercado, dentre outras coisas. Os contextos da brincadeira criam possibilidades de instauração de movimentos múltiplos, nos quais processos e práticas são projetados em diferentes perspectivas, produzindo atuações no cotidiano escolar que se tornam fontes coletivas de diálogo, recriação e ressignificação da própria existência.

$\mathrm{Na}$ perspectiva de Celso Antunes (1998), o conceito de inteligência surge como a capacidade de compreensão das coisas, um produto oriundo da operação cerebral, que leva a solução de problemas de maneira mais eficaz, em que a formação de ideias, o juízo e o raciocínio constituem-se em elementos essenciais à inteligência. Nesse sentido, o contexto ambiental cognitivo (sócio-histórico e cultural) é parte constituinte das nossas inteligências, pois sem a coletividade, não teríamos uma herança cultural, crenças, escritas, tradições dentre outras formas de expressão e existência. A partir desses vínculos, Antunes (1998, p. 12) associa a inteligência ao estado emocional de felicidade, pois relaciona que "[...] quanto mais inteligentes nos tornamos, mais facilmente construímos nossa felicidade". Mesmo que os estudos sobre o funcionamento da inteligência tenham iniciado há pouco tempo, Antunes (1998, p. 16) considera que é possível afirmar que a inteligência "[...] é produto de uma carga genética que vai muito além de seus avós, mas que alguns detalhes da estrutura da inteligência podem ser alterados com estímulos significativos aplicados em momentos cruciais do desenvolvimento humano". De acordo com o autor, esse aumento pode variar entre $30 \%$ e $50 \%$, sendo mais intenso na execução de algumas operações do que em outras. Um ambiente estimulador é fundamental para a ampliação das múltiplas inteligências.

Cabe lembrar que assim como o corpo humano envelhece a inteligência também. Para Antunes (1998), estudos mostram que ao desempenhar funções simples são acionadas diferentes partes do cérebro e, ainda, que homens e mulheres de origem ocidental, apresentam diferenças nas estruturas cerebrais, em decorrência da herança histórica de vida de ambos, as quais modelaram as formas desiguais de utilização dos dois hemisférios cerebrais. Por conta dessas investigações constata que o envelhecimento da inteligência pode ocorrer por falta de estímulos, mas não atinge todas as inteligências ao mesmo tempo. Cada uma das inteligências possui o que denomina de janela de oportunidades, em que sua abertura e seu fechamento dependem de cada inteligência (ANTUNES, 1998). Sem as experiências que levam à aprendizagem o cérebro se resume a uma massa cinzenta. Isso significa que as tramas neurais (sinapses) precisam ser construídas com desafios e estímulos, desde o nascimento até a vida adulta. Os hemisférios irão se especializando lentamente até os cinco anos e rapidamente até os 16, de maneira desigual em cada hemisfério e inteligência. As janelas de oportunidades representam os períodos válidos para ampliação das capacidades das diferentes inteligências. $O$ fechamento da janela não significa impedimento da aprendizagem, mas sim uma dificuldade maior para aprender.

Antunes (1998) destaca que, de acordo com o cientista e pesquisador Howard Gardner que em 1983 publicou seus estudos sobre a Teoria das Inteligências Múltiplas —, há oito pontos diferentes no cérebro em que cada um abriga uma forma específica de saber / competência e processamento de informações, denominados por ele de inteligências múltiplas, quais sejam: linguística ou verbal, lógico-matemática, espacial, musical, cinestésica corporal, naturalista e as inteligências pessoais (intrapessoal e interpessoal). Para Gardner, o estudo sobre a teoria das 
inteligências múltiplas vem contrariar a visão tradicional que se tinha, até então sobre o conceito de inteligência, visto que:

Numa visão tradicional, a inteligência é definida operacionalmente como a capacidade de responder a itens em testes de inteligência. A inferência a partir dos resultados de testes, de alguma capacidade subjacente, é apoiada por técnicas estatísticas que comparam respostas de sujeitos em diferentes idades; a aparente correlação desses resultados de testes através das idades e através de diferentes testes corrobora a noção de que a faculdade geral da inteligência, g, não muda muito com a idade ou com treinamento ou experiência. Ela é um atributo ou faculdade inata do indivíduo. (GARDNER, 1995, p. 21).

Relaciona-se o conceito de inteligência pautado nos estudos de Gardner (1995) com uma das principais perspectivas sobre a necessidade de preservação do ser humano em Rousseau, sobre uma educação natural, que privilegie as faculdades humanas naturais, cuidando do desenvolvimento interno da criança desde seu nascimento. Tudo isso como forma de potencializar a aprendizagem pelos sentidos, para que assim possa viver bem e feliz.

Uma criança passa assim seis ou sete anos dessa maneira nas mãos das mulheres, vítimas dos caprichos delas e do seu próprio. E depois de lhe ensinar isto ou aquilo, isto é, depois de ter sobrecarregado sua memória com palavras que não pode entender ou com coisas que em nada lhe auxiliam, depois de ter abafado o natural com paixões que se incitam, entrega-se esse ser factício nas mãos de um preceptor, o qual acaba de desenvolver os germens artificiais que já encontra formados e lhe ensina tudo menos a se conhecer, menos a tirar proveito de si mesmo, menos a saber viver bem e se tornar feliz. Finalmente quando essa criança, escrava e tirana, cheia de conhecimentos e desprovida de sentidos, igualmente débil de corpo e de alma, é jogada no mundo mostrando sua inépcia, seu orgulho e todos os seus vícios, ela faz com que se deplorem a miséria e a perversidade humanas. Enganamo-nos: esse é o homem de nossa fantasia, o da natureza é diferente. (ROUSSEAU, 1995, p. 22).

Tendo por base esses estudos comportamentais do cérebro humano sobre o conceito de inteligência a partir de Gardner, que, assim como Antunes (1998) reforça, a escola não pode mais configurar-se como um espaço transmissor de informações, mas necessita reinventar-se, assumindo papel de ambiente estimulador das diferentes inteligências e capacidades inatas, permitindo ao estudante desenvolver saberes, artes do fazer e a ter atitude de aprender a aprender. Nessa lógica, o professor passa a ser um estimulador das múltiplas inteligências e, consequentemente, um agente orientador da felicidade humana (ANTUNES, 1998). Afinal de contas, "[...] só por meio do relacionamento humano, devidamente orientado, o indivíduo poderá desenvolver a consciência do problema social e da forma como melhor enfrentá-lo" (PAIVA, 2019, p. 16).

\section{CONSIDERAÇÕES FINAIS}

Concluímos com a explicitação de Klein (2019, p. 26) para uma metáfora de Rousseau acerca do deslocamento do curso de um rio, que nos instiga a pensar as complexidades da educação na atualidade.

Não se trata de represá-lo ou de diluí-lo, pois, uma vez que o homem vive em sociedade e o surgimento do amor próprio é inevitável, cabe apenas deslocar o 
seu curso, para que ele não se direcione para o egoísmo ou para o amor próprio inflamado e sim para o interesse comum e para a virtude moral.

Cabe hoje acompanhar a evolução dos processos de formação cultural e construção do conhecimento assumidos na indissociável sociabilidade do ensino, que movimenta o agir humano, como forma de estimular as inter-relações com os outros e com a natureza, sensibilizando também o encontro com as diferenças, a imaginação e a formação de mundos. Aqui podemos citar como exemplo o que defende Rousseau (1995, p. 183), "[...] todo apego é sinal de insuficiência; se cada um de nós não tivesse nenhuma necessidade dos outros, não pensaria em unir-se a eles. Assim, de nossa mesma imperfeição nasce nossa frágil felicidade”. Daí que nos relacionamos com os outros para compreendermos a própria identidade e nossas naturezas, sendo que a garantia do apego dos outros por nós é condição para enfrentarmos os nossos próprios inacabamentos, limites, conflitos e sofrimentos, que se desenrolam nas esferas científica, pedagógica, artística e social. Os estudos acerca do efeito educativo da obra de Rousseau indicam que a influência do meio ambiente natural precisa ser parte das relações humanas na vida educativa em sociedade, pois, "[...] o reconhecimento do outro é um modus operandi muito importante para a Educação, que lhe auxilia provocando mudanças externas e internas concomitantemente", e nós seguidamente ignoramos as condições de possibilidade que a própria natureza nos permite cultivar, no espaço aberto da ação e da livre expressão do sujeito (TREVISAN, ROSA, 2018, p. 832).

Em suma, tanto Rousseau quanto Piaget destacam que a criança precisa ter a oportunidade de brincar e interagir e isso desenvolve a dimensão da empatia, por meio de afetos ou jogos de linguagem com o outro na realidade (concreta, imaginada ou interconectada), rumo ao "desenvolvimento de uma pedagogia socializadora" (PAIVA, 2019, p. 7). Esse fortalecimento da interação e construção de relações estabelecidas com o meio e com o objeto, a partir das condições metafóricas, sociais, históricas e culturais, mostram-se fundamentais ao desenvolvimento real, ativo, potencial ou proximal com o outro. Se a criança cresce no meio social e aprende a dialogar e lançar perguntas para resolver problemas, então, o que a diferencia é a capacidade sensibilizada pela convivência para a realização de uma atividade ou se ainda está no processo de maturação.

Por fim, Rousseau destaca a valorização das experiências com o meio para que ocorra a evolução humana, considerando a prática como um fator fundamental para o processo de ensino e de aprendizagem, porém, não classificando por níveis de desenvolvimento. $\mathrm{Na}$ tentativa de confrontar as distorções e desigualdades humanas e sociais constatadas com a questão da educabilidade como propulsora dos laços socioculturais, podemos concluir com Dalbosco (2019, p. 2-3) "[...] que é a capacidade de aperfeiçoamento do ser humano que possibilita a educabilidade do aspecto destrutivo do amor próprio". A valorização da autonomia da criança nos processos de ensino fortalece a compreensão dos próprios conceitos e significados, a partir de diferentes interações e relações com o outro e com os objetos. Contudo, a aprendizagem social se torna efetiva à medida que é estimulada e desafiada através de experiências, pois elas têm o poder de desacomodar, perturbar, projetando o desenvolvimento de habilidades, saberes e atitudes, para a própria reinvenção a cada desafio.

De qualquer modo, a formação individual ocorre por meio da permanente tensão entre as pressões externas do meio e a capacidade de seleção e reelaboração dessas pressões feitas pelo próprio sujeito educacional. Plasticidade como educabilidade é, então, a capacidade humana de enfrentar essa tensão sem sucumbir às pressões do ambiente e nem se fechar em sua própria interioridade. (DALBOSCO, 2019, p. 18). 
Esses desafios deveriam ser propostos continuamente, como possibilidade de coordenar as ações educacionais e as orientações próprias das experiências no mundo da vida. Em síntese, cabe manter abertos os canais de comunicação e questionamento aos processos de ensino sobre as abordagens clássicas das investigações educativas, considerando as múltiplas capacidades e pluralidades do ser humano para tecer novas compreensões pedagógicas à educação contemporânea.

\section{REFERÊNCIAS}

ANTUNES, Celso. As inteligências múltiplas e seus estímulos. Campinas, São Paulo: Papirus, 1998.

DALBOSCO, Claudio Almir. Condição humana e educabilidade: um problema nuclear das teorias educacionais clássicas. Revista Brasileira de História da Educação, v. 18, e0132018, jan. 2019. Disponível em DOI: http://doi.org/10.4025/rbhe.v18.2018.e013.

HERMANN, Nadja. Hermenêutica e educação. Rio de Janeiro: DP\&A, 2003.

GARDNER, Howard. Inteligências múltiplas: a teoria na prática. Trad. Maria Adriana Veríssimo Veronese. Porto Alegre: Artes Médicas, 1995.

GÓMEZ, Angel Pérez. Os processos de ensino-aprendizagem: análise didática das principais teorias da aprendizagem. In: SÁCRISTÁN, J. Gimeno; GÓMEZ, Angel Pérez (org.). Compreender e transformar o ensino. Trad. Ernani F. da Fonseca Rosa. Porto Alegre: ArtMed, 1998.

KLEIN, Joel Thiago. A questão da natureza humana: Kant leitor de Rousseau. Trans/Form/Ação, Marília, v. 42, n. 1, p. 9-34, abr. 2019. Disponível em DOI: http://doi.org/10.1590/01013173.2019.v42n1.02.p9.

PAIVA, Wilson Alves de. As relações humanas como uma questão pedagógica: a conectividade humana em Rousseau. Educação e Pesquisa, São Paulo, v. 45, e191470, ago. 2019. Disponível em DOI: http://doi.org/10.1590/s1678-4634201945191470

PIAGET, Jean. Epistemologia genética. Tradução Álvaro Cabral. 3. ed. São Paulo: Martins Fontes, 2007.

REGO, Teresa Cristina. Vygotsky: uma perspectiva histórico-cultural da educação. 19. ed. Petrópolis, Rio de Janeiro: Vozes, 2008.

ROUSSEAU, Jean-Jacques. Emílio ou da Educação. São Paulo: Martins Fontes, 1995. Disponível em http://www.ensinarfilosofia.com.br/wp-content/uploads/2017/03/Rousseau-Emilio-Ou-Da-

Educacao.pdf. Acesso em 3 set. 2017.

STRECK, Danilo R. Roussean \& a educação. Belo Horizonte: Autêntica, 2004.

SOËTARD, Michel. Jean-Jacques Rousseau. Recife: Fundação Joaquim Nabuco: Ed. Massangana, 2010.

TREVISAN, Amarildo Luiz; ROSA, Geraldo Antonio da. Modernidade em (des)encontro: a educação entre expressivismo e objetividade. Avaliação: Revista da Avaliação da Educação Superior, Campinas, v. 23, n. 3, p. 815-833, dez. 2018. Disponível em DOI: http://doi.org/10.1590/s141440772018000300014.

VYGOTSKY, Lev S. Pensamento e linguagem. Rio de Janeiro: Martins Fontes, 1991.

VYGOTSKY, Lev S. A formação social da mente. São Paulo: Martins Fontes, 1984.

Submetido em julbo de 2019 Aprovado em julho de 2020 


\section{Informações das autoras}

Míriam Benites Rios

Assessoria na Coordenadoria de Graduação do Centro Universitário Metodista (IPA/RS) e membro do Núcleo de Estudos sobre Tecnologias na Educação (NETE/UNILASALLE/CNPq)

E-mail:miriambrios@gmail.com

ORCID: http://orcid.org/0000-0002-4788-0661

Link Lattes: http://lattes.cnpq.br/2509757536200007

Lilian Soares Alves Branco

Centro Universitário Leonardo da Vinci (UNIASSELVI, Brasil) e membro do Núcleo de Estudos sobre Tecnologias na Educação (NETE/UNILASALLE/CNPq)

E-mail: lilian.sab@gmail.com

ORCID: http://orcid.org/0000-0002-6629-6006

Link Lattes: http://lattes.cnpq.br/4441935444962342

Elaine Conte

Programa de Pós-Graduação em Educação da Universidade La Salle (PPGE/UNILASALLE, Canoas/RS)

E-mail: elaine.conte@unilasalle.edu.br

ORCID: http://orcid.org/0000-0002-0204-0757

Link Lattes: http://lattes.cnpq.br/8885390885955168 